\title{
EFFECT OF SOME EFFECTIVE PARAMETERS ON COD REMOVAL FROM NAM SON LANDFILL LEACHATE BY ELECTROCOAGULATION
}

\author{
Le Thanh Son ${ }^{1,}$, Le Cao Khai ${ }^{2}$, Doan Tuan Linh ${ }^{1}$, Doan Thi Anh ${ }^{1}$ \\ ${ }^{1}$ Institute of Environmental Technology, Vietnam Academy of Science and Technology, 18 \\ Hoang Quoc Viet Road, Cau Giay District, Ha Noi, Viet Nam \\ ${ }^{2}$ Faculty of Chemistry, Hanoi Pedagogical University $N^{\circ} 2$, Nguyen Van Linh Street, \\ Xuan Hoa Ward, Phuc Yen, Vinh Phuc, Viet Nam \\ "Email: thanhson96.le@gmail.com
}

Received: 15 February 2017; Accepted for publication: 28 July 2017

\begin{abstract}
Leachate becomes ahead of wastewaters as being the most difficult to treat due to its complex and widely variable composition. In this research, the leachate treatment performance by electrocoagulation (EC) was studied. The samples of leachate were taken from Nam Son landfill in Hanoi. The effects of factors namely current intensity, electrolysis time, initial $\mathrm{pH}$ and anode materials on the EC performance were investigated via chemical oxygen demand (COD) removal efficiencies. The input leachate properties were obtained as $\mathrm{COD}, \mathrm{NH}_{4}{ }^{+}$and $\mathrm{pH}$ in the range of around $6247 \pm 295,1270 \pm 38 \mathrm{mg} / \mathrm{l}$ and $8 \pm 0.1$, respectively. Mono-polar electrocoagulation unit was set up in a batch system for leachate treatment with iron electrodes and approximately 1.8 litter of leachate. Firstly, with the increase in current (1 to 4A), the COD removal efficiencies increased from 50.00 to $78.57 \%(\mathrm{pH}=8$ and operating time $=40 \mathrm{~min}$ ). Secondly, by the increase in operating time, the treatment performance also went up significantly in first $40 \mathrm{~min}$, then nearly level-off at above $73 \%(\mathrm{pH}=8$, current intensity $=3 \mathrm{~A})$. In addition, the effect of $\mathrm{pH}$ in range of 5 to 10 on the electrocoagulation process was studied and it showed the highest treatment efficiencies in neutral and mild alkaline medium, especially between $6<\mathrm{pH}<8$. Finally, the electrode materials made of iron and aluminum were investigated and the result indicated that when the iron anodes were replaced by aluminum, the COD removal efficiency experienced a considerable decline, from 70 to $37.93 \%$ (pH $=8$ and operating time $=40 \mathrm{~min}$ ). In combination of all experiments, the optimum operating conditions were achieved as iron electrodes, current intensity of 3A, electrolysis time of $40 \mathrm{~min}$, the raw $\mathrm{pH}$ with iron electrodes, resulting the maximum COD removal efficiencies of $73.21 \%$. As a result, the electrocoagulation can be applied to leachate pre-treatment.
\end{abstract}

Keywords: electrocoagulation, landfill leachate, COD removal efficiency, current intensity, operating time, $\mathrm{pH}$, electrode materials. 


\section{INTRODUCTION}

Landfilling is the most widely-used method for the solid waste treatment. Landfill leachate is generated as a consequence of precipitation, surface run-off and infiltration or intrusion of groundwater percolating through the landfill [1]. Leachate is a high strength toxic effluent with a complex matrix of both organic and inorganic pollutants which always varies and depends on several factors especially waste composition, landfill age, seasonal weather variations, levels of precipitation, landfill temperature. Hence, leachate becomes ahead of wastewaters as being the most difficult to treat. There are number of treatment methods that have been used to treat the leachate, such as biological treatment method, advanced oxidation techniques, wetland application, membrane processes and coagulation-flocculation methods [2]. However, such methods have some shortages namely decreasing treatment efficiencies and increasing cost due to the significant change in leachate characteristics with advancing years of the landfill [1]. Therefore, some effective and economical treatment methods need to be developed to solve these problem. One of the simple, effective and economic-efficient is electrocoagulation (EC) which is successful electrochemical methods for many kinds of wastewater treatment in the world [3]. Electrocoagulation (EC) is an alternative waste water treatment that combines electrochemical processes with conventional chemical coagulation, which bases on three main technologies namely electrochemistry, coagulation and flotation. There are two widely-used electrode material being iron and aluminum electrodes. Fe/Al is dissolved from the anode generating corresponding metal ions, which almost immediately hydrolyze to polymeric iron or aluminum hydroxide. These polymeric hydroxides are excellent coagulating agents. The pollutants from wastewater were treated either by complexation or by electrostatic attraction, adsorption, then removed by an electro-flotation.

Electrocoagulation is promising as an economical and environmental choice for treatment of wastewater and other related water management issues. EC is an efficient technique since adsorption of hydroxide on mineral surfaces are a 100 times greater on 'in situ' rather than on precipitated hydroxides when metal hydroxides are used as coagulant [4]. It is cost-effective, and easily operable because of simple equipment and low start-up and operating cost. Besides, the 'electron' is the main reagent and does not require addition of the reagents/chemicals, which will minimize the sludge generation to a great extent and eventually eliminate secondary pollution as well as some of the harmful chemicals used as coagulants in the conventional effluent treatment methods. EC process can effectively destabilize smallest colloidal particles and generates lower quantity of sludge compared to several conventional chemical and biological techniques because the smallest charged particles have greater probability of being coagulated by the electric field that sets them in motion. In addition, the EC technique can be conveniently used in rural areas where electricity is not available, since a solar paned attached to the unit may be sufficient to carry out the process. Lastly, gas bubbles produced during electrolysis can enhance flotation.

The purpose of this paper is to study the removal efficiency of COD from landfill leachate by electrocoagulation.

\section{MATERIALS AND METHODS}

\subsection{Landfill site description and leachate characteristics}

The research was carried out in Nam Son landfill being one of the biggest and most modern landfill in Vietnam, which is located in Soc Son district and about $50 \mathrm{~km}$ from the Hanoi city 
center. This landfill with area of 83.5 hectares has started mechanized operation in 1999 and expanded to 112 hectares in 2015. Currently, Nam Son landfill receives about 4300 to 4500 tons of waste per day and approximately $2000 \mathrm{~m}^{3}$ leachate, yet only $1500 \mathrm{~m}^{3}$ leachate is treated daily [5].

The samples used in the experiments were collected from leachate reservoir in Nam Son landfill in June, 2016 and stored in obscurity at $\mathrm{T}=4{ }^{\circ} \mathrm{C}$ prior to the experiments. The properties of leachate were analyzed and the values are given in Table 1.

Table 1. The properties of leachate from Nam Son landfill.

\begin{tabular}{|c|c|c|}
\hline No. & Leachate properties & Properties \\
\hline 1 & $\mathrm{COD}(\mathrm{mg} / \mathrm{l})$ & $6247 \pm 295$ \\
\hline 2 & $\mathrm{NH}_{3}-\mathrm{N}(\mathrm{mg} / \mathrm{l})$ & $1270 \pm 38$ \\
\hline 3 & $\mathrm{NO}_{3}{ }^{-}(\mathrm{mg} / \mathrm{l})$ & 2.1 \\
\hline 4 & Conductivity $(\mathrm{mS} / \mathrm{cm})$ & 10.5 \\
\hline 5 & $\mathrm{pH}$ & $8 \pm 0.1$ \\
\hline 6 & $\mathrm{TDS}(\mathrm{ppm})$ & 5100 \\
\hline
\end{tabular}

\subsection{Reactor design}

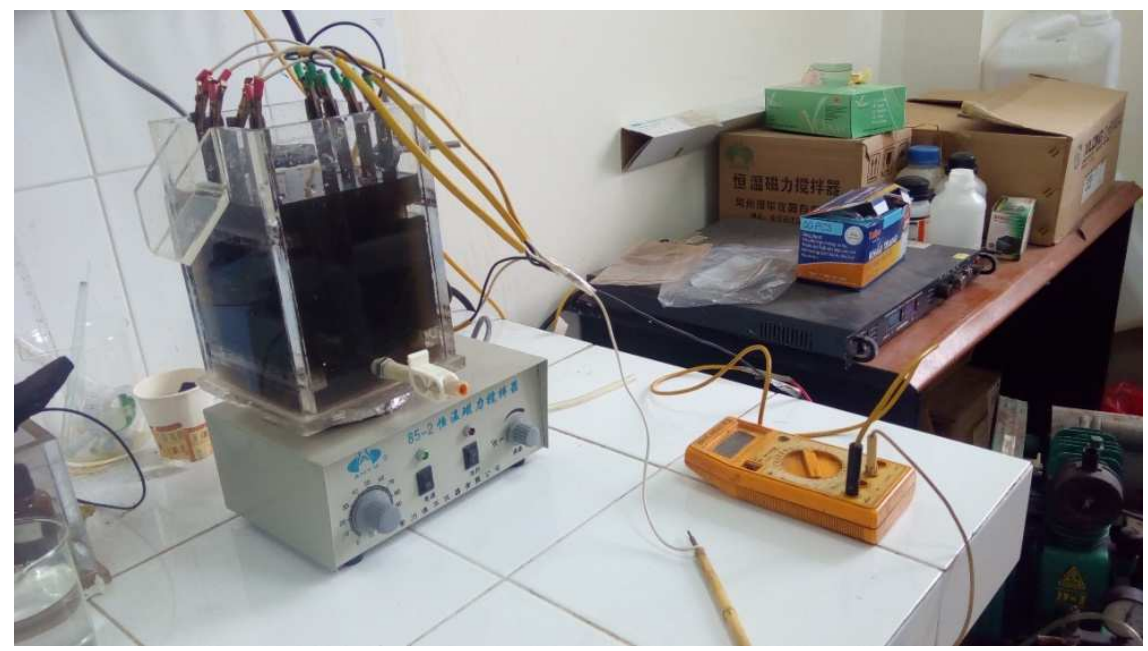

Figure 1. The electrocoagulation reactor mode.

The experimental setup is shown in Fig. 1. The electrocoagulation reactor was made of acrylic material with a dimension of $14 \mathrm{~cm}$ (width) _ $14 \mathrm{~cm}$ (length) _ $21 \mathrm{~cm}$ (depth) and the thickness of $1 \mathrm{~cm}$. The mono-polar electrocoagulation unit consisted of eight electrodes which were totally connected directly to a Direct Current (Programmable PFC D.C.Supply 40V/30A, VSP 4030, BK Precision). Each electrode was made of iron or aluminum with the dimension of $11 \mathrm{~cm} \times 10 \mathrm{~cm}$, the electrodes were submerged in leachate and the distance between electrodes was $1 \mathrm{~cm}$. In this discontinuous system, approximately 1.8 liter leachate was injected into the water cell and the solution was agitated with a magnetic stirrer by the speed of $200 \mathrm{rpm}$. During 
experiment, the effects of some factors namely current intensity, operating time, $\mathrm{pH}$ and electrode materials on COD removal efficiency were investigated. At the end of each EC treatment study, a solution with flocks was allowed to settle for $1 \mathrm{~h}$ in the container before chemical analysis. The samples for chemical analysis were taken from limpid phase. Neither centrifuging nor filtration was performed in this study.

\subsection{Analysis}

The COD and pH were measured by the dichromate method (TCVN 6491:1999, corresponding to ISO 6060:1989) and pH monitor (HANNA HI 991001), respectively. All the runs were carried out at room temperature of 25 centigrade.

\section{RESULTS AND DISCUSSIONS}

\subsection{Effects of current intensity and operating time}

The effects of operating time and current intensity were investigated simultaneously with the iron electrodes in range of 10 to 80 minutes and the intensity variation of 1,2, 2.5, 3 and $4 \mathrm{~A}$ respectively by the following conditions: $\mathrm{pH}=8$ ( $\mathrm{pH}$ of input leachate). The samples were taken in the electrolysis time of 10,20,30, 40,60 and $80 \mathrm{~min}$ and then analyzed COD index to assess the leachate treatment performance by electrocoagulation.

Obviously, the leachate color changed from dark to fairly clear and mildly greenish after treatment. The amount of precipitation, flocks and floats increased significantly by time and then turned yellow- brown color.

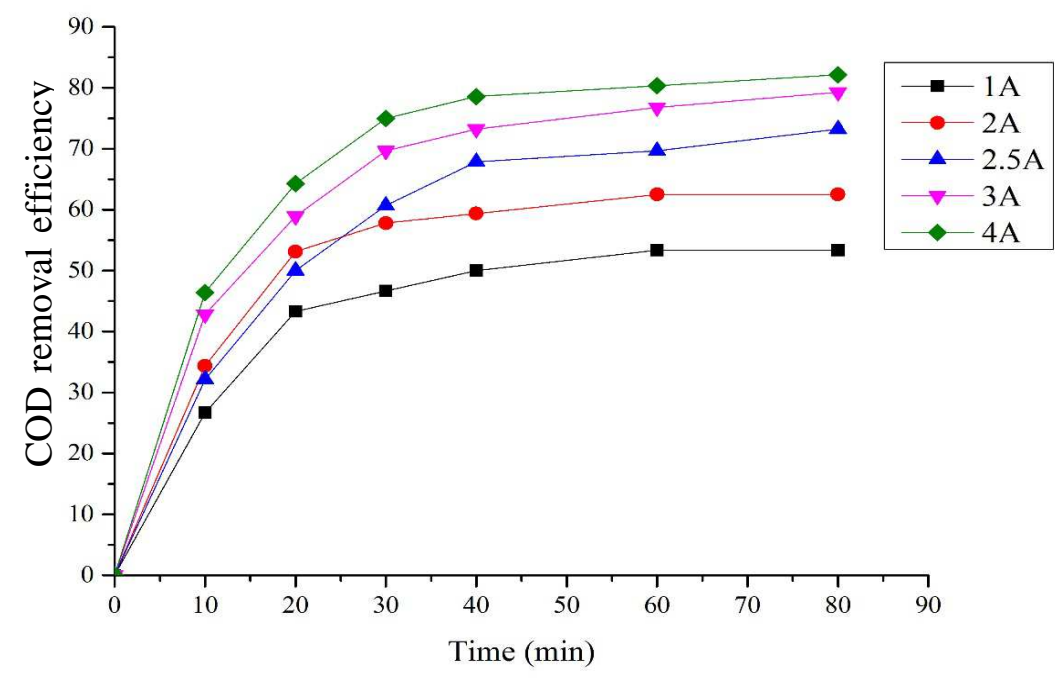

Figure 2. The effects of current intensity and operating time on COD removal efficiency.

Firstly, the current intensity played a vital role in electrocoagulation process. As shows in Fig. 2, the COD treatment yield was directly proportional to current intensity, as increase in current intensity, the COD removal efficiency also increased. The removal efficiency of COD at current intensity 1 to 4 A rose from 46.67 to $75 \%$ in the treated time of $30 \mathrm{~min}$. The figure demonstrated that the COD removal percentage at the intensity of 3 and $4 \mathrm{~A}$ were not 
considerably different, at 79.29 and $82.69 \%$ respectively at $80 \mathrm{~min}$ of electrolysis time. Hence, the current intensity of $3 \mathrm{~A}$ was chosen to set up the next experiments in order to save energy. In fact, by the increase in current intensity, the extent of anodic dissolution of iron increased, resulting in a greater amount of hydroxide flocks and coagulant dosage for the pollutants treatment, which was totally fitting with the Faraday's law. In addition, the rate of bubblegeneration went up and the bubble size went down and their density increased with the rise in current intensity, bringing about a faster removal of contaminants by $\mathrm{H}_{2}$ flotation.

Apart from the electrocoagulation efficiency, COD of leachate can reduce due to electrolysis process. It is undouble that leachate electrolysis process might produce free-radicals being one of the strong oxidants such as $\mathrm{OH}^{*}, \mathrm{H}_{2} \mathrm{O}_{2}$ and so on. These radicals tends to oxidize organic compounds creating $\mathrm{CO}_{2}$ and $\mathrm{H}_{2} \mathrm{O}$, resulting in a decrease in COD. When the current intensity increases, the larger amount of these radicals are produced affecting considerably COD treatment ability of electrocoagulation process.

Secondly, electrolysis time was also investigated as an influence factor. As can be seen in Fig. 2, with any value of current intensity, the COD removal percentage skyrocketed at the first period of electrolysis time. For instance, with current intensity of $1 \mathrm{~A}$ and $4 \mathrm{~A}$, the COD treatment yield went up to approximately $26.67 \%$ and $46.43 \%$ in 10 first min, then climbed to about 50.00 and $78.57 \%$ at the time of $40 \mathrm{~min}$, respectively. Moreover, there existed a noticeable point that the COD treatment yield tended to remain stably after 40 electrolysis minutes; in detail, at above $73 \%$ COD removed with the current intensity of 3A. Obviously, when the operating time increased, the concentration of iron ions and their hydroxide flocks increased, also the speed of bubble-formation increased. The contaminants in leachate were eliminated by the impact of coagulation and flotation. High electrical energy consumption with the rise in time, as a result, 40 minutes was required to be the optimum operating time.

\subsection{Effect of pH}

One of the most important factors influenced significantly on electrocoagulation process was definitely $\mathrm{pH}$. In order to examine its effect, the initial $\mathrm{pH}$ was adjusted to 5, 6, 7, 8, 9 and 10. The results of COD analysis process were indicated in following Fig. 3 with constant operating time of $40 \mathrm{~min}$ and current intensity of $3 \mathrm{~A}$.

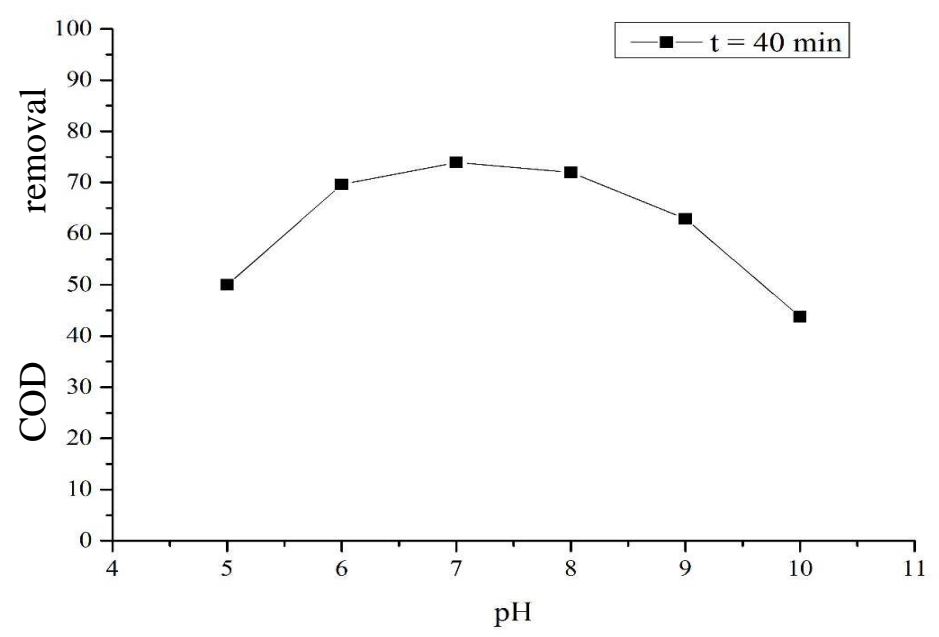

Figure 3. The effect of initial $\mathrm{pH}$ on COD removal efficiency. 
It was evident that electrocoagulation process worked effectively in the range of $\mathrm{pH}$ from 6 to 8 in COD removal, around $70 \%$. The maximum removal of COD was observed $73.91 \%$ at initial $\mathrm{pH}$ of 7 . Both the acidic and basic condition experienced a considerably decrease in COD removal efficiency. This result can be explained by the distribution of iron ionic species. Different hydroxide species formed during electrocoagulation are affected by $\mathrm{pH}$. The surface charge of the particles can also be modified by a change in $\mathrm{pH}$, which definitely influence to the removal ability of contaminants. The species are useful for removal of pollutants, which are stable and insoluble. According to predominance zone diagram for iron (III), at acidic conditions the species of $\mathrm{Fe}^{3+} ; \mathrm{Fe}(\mathrm{OH})_{2}^{+} ; \mathrm{Fe}(\mathrm{OH})^{2+}$ ions are dominant and at alkaline condition $\mathrm{Fe}(\mathrm{OH})_{4}{ }^{-}$ ion is dominant and these species are soluble; moreover, the solubility of $\mathrm{Fe}(\mathrm{OH})_{3(\mathrm{~s})}$ increases and these species are not effective for removal of COD and diesel. However, in neutral $\mathrm{pH}$, $\mathrm{Fe}(\mathrm{OH})_{3(\mathrm{~s})}$ is stable, insoluble and available for pollutant adsorption from wastewater. Thus, $\mathrm{Fe}(\mathrm{OH})_{3(\mathrm{~s})}$ has the major role in the removal of COD. To take into account the raw leachate $\mathrm{pH}$, it was not necessary to regulate initial $\mathrm{pH}$ of leachate.

The constituents of hydrocarbon molecules are hydrophobic and nonpolar neutral; hence, they have probably been removed from the wastewater through the formation of surface complexes by gelatinous $\mathrm{Fe}(\mathrm{OH})_{3(\mathrm{~s})}$ precipitate. The active sites on hydrocarbon molecules complex present the surfaces of ferric hydroxide flocks which are growing (co-precipitation) and undergo physical adsorption onto the amorphous $\mathrm{Fe}(\mathrm{OH})_{3(\mathrm{~s})}$ flocks using van der Waals forces [6]. Based on the following reactions, the mechanism involved in the removal of petroleum hydrocarbons can be simplified [6]. Formation of ferric hydroxide (at $6<\mathrm{pH}<9$ ):

$$
\begin{gathered}
\mathrm{Fe}^{3+}{ }_{(\mathrm{aq})}+3 \mathrm{OH}_{(\mathrm{aq})}^{-}=>\mathrm{Fe}(\mathrm{OH})_{3(\mathrm{~s})} \\
\text { Adsorption of hydrocarbons }(\mathrm{HC}) \\
\left.\mathrm{Fe}(\mathrm{OH})_{3(\mathrm{~s})}+\mathrm{HC}=>\mathrm{Fe}(\mathrm{OH})_{3}-\mathrm{HC}\right)_{\mathrm{floc}}
\end{gathered}
$$

$\left(\mathrm{Fe}(\mathrm{OH})_{3}-\mathrm{HC}\right)$ flocks can attach together and flocculate; thus, contaminants are separated from the wastewater by settling, flotation or filtration [6]. This is consistent with the findings of Li X. et al. [7] and Kobya M. et al. [8].

\subsection{Effect of anode materials}

Different anode electrode materials affect the performance of the electrocoagulation process. The most widely-used electrode materials are aluminum and iron for their cheap, readily available, and effective. In this study, $\mathrm{Fe}$ and $\mathrm{Al}$ electrodes were compared on the condition that: 3 A current intensity, input leachate $\mathrm{pH}(8.0)$.

By observation during experiment, for color and turbidity, the resulting effluent treated with aluminum was found clear and stable, whereas that treated with iron electrodes appeared greenish first, and then turned yellow and turbid. The green and yellow colors could have resulted from $\mathrm{Fe}(\mathrm{II})$ and $\mathrm{Fe}(\mathrm{III})$ species generated during the electrolysis and characterized by their yellow-brown color.

It can be seen evidently from Fig. 4 that Fe-electrode had a higher treatment efficiency than $\mathrm{Al}$ one for COD removal. In detail, the COD removal efficiency by iron electrodes increased by 20 to $30 \%$ compared to the aluminum anode in the first 40 min electrolysis time because the settle ability of particle formed by $\mathrm{Fe}(\mathrm{OH})_{3}$ is better than that formed by $\mathrm{Al}(\mathrm{OH})_{3}$. The result shown the same trend with the research performed by Li X. et al. [7] and Kobya M. et al. [8] in contrast, there exits some disagreement namely the study by Ilhan F. et al. [2]. 


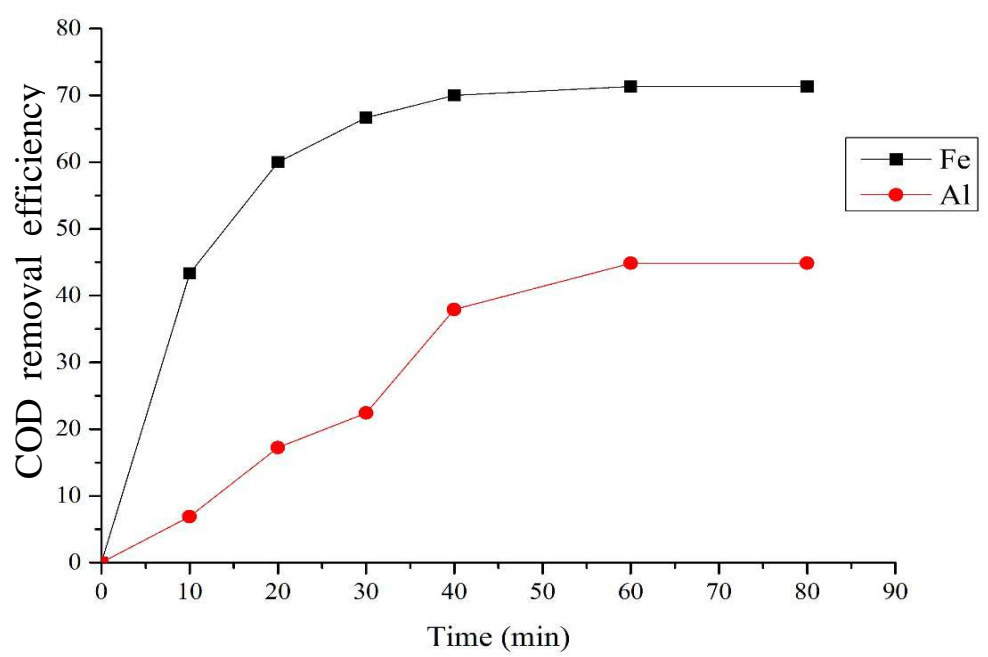

Figure 4. The effect of $\mathrm{Al}$ and Fe electrodes on COD removal efficiency.

\section{CONCLUSION}

The study indicated several properties of Nam Son landfill leachate, $\mathrm{COD}, \mathrm{NH}_{4}{ }^{+}$and $\mathrm{pH}$ in particular with the concentration in the range of approximately $6247 \pm 295,1270 \pm 38 \mathrm{mg} / \mathrm{l}$ and 8 respectively. With the increase in current ( 1 to $4 \mathrm{~A}$ ), the COD removal efficiencies increased from approximately 50 to $78 \%(\mathrm{pH}=8$ and operating time $=40 \mathrm{~min})$. Furthermore, the research on effect of $\mathrm{pH}$ showed the highest treatment efficiencies in neutral and mild alkaline medium, especially between $6<\mathrm{pH}<8$. Besides, when the iron anodes were replaced by aluminum, the COD removal efficiency experienced a considerable decline, from 70 to $37.93 \%$ (pH $=8$ and operating time $=40 \mathrm{~min}$ ). The optimum condition for Nam Son leachate treatment by electrocoagulation was obtained as current intensity of $3 \mathrm{~A}$, electrolysis time of $40 \mathrm{~min}$, raw $\mathrm{pH}$ (around 8) and iron electrodes, resulting the maximum COD removal efficiencies of $73.21 \%$. In conclusion, electrocoagulation can be applied to leachate pre-treatment.

Acknowledgements. This work was supported financially by Vietnam Academy of Science and Technology (VAST), under VAST07.01/16-17 project.

\section{REFERENCES}

1. Wu J. J., Wu C. C., Ma H. W., and Chang C. C. - Treatment of landfill leachate by ozone based advanced oxidation processes, Chemosphere 54 (2004) 997-1003.

2. Ilhan F., Kurt U., Apaydin O. and Gonullu M. T. - Treatment of leachate by electrocoagulation using aluminum and iron electrodes, J. Hazard. Mater. 154 (2008) 381-389.

3. Linares-Hernández I., Barrera-Díaz C., Roa-Morales G., Bilyeu B. and Ureña-Núñez F. Influence of the anodic material on electrocoagulation performance, Chem. Eng. J. 148 (2009) 97-105. 
4. Mollah M. Y., Morkovsky P., Gomes J. A, Parga J. and Cocke D. L. - Fundamentals, present and future perspectives of electrocoagulation, J. Hazard. Mater. 114 (2004) 199-210.

5. Khai N. M. and Trang H. T. Q. - Chemical Precipitation of Ammonia and Phosphate from Nam Son Landfill Leachate, Hanoi, Iranica J. Energy \& Environment 3 (2012) 32-36.

6. Moussavi G., Khosravi R. and Farzadkia M. - Removal of petroleum hydrocarbons from contaminated groundwater using an electrocoagulation process: batch and continuous experiments, Desalination 278 (2011) 288-294.

7. Li X., Song J., Guo J., Wang Z. and Feng Q. - Landfill leachate treatment using electrocoagulation. Procedia Environ. Sci. 10 (2011) 1159-1164.

8. Kobya M., Can O.T. and Bayramoglu M. - Treatment of textile wastewaters by electrocoagulation using iron and aluminum electrodes. J. Hazard. Mater. B100 (2003) 163-178. 